\title{
Effects of Estradiol on Autophagy and Nrf-2/ARE Signals after Cerebral Ischemia
}

\author{
Litao Li Jinghong Chen Sujuan Sun Jingru Zhao Xiaoli Dong Jianhua Wang \\ Department of Neurology, Hebei General Hospital, Shijiazhuang, Hebei, China
}

\section{Key Words}

Cerebral ischemia $\cdot$ Autophagy $\cdot$ Female sex hormones $•$ Pro-inflammation $•$ Oxidative stress

\begin{abstract}
Background/Aims: Estradiol (EST) reduces the risk of stroke and decreases the incidence and progression of the disease because of its neuroprotective roles in inhibiting cell death that occurs in response to a variety of neuronal stimuli such as inflammation and oxidative stress. In this study, we determined the role played by autophagy and Nrf2-ARE signal pathways in the hippocampus regions in modulating cerebral ischemia under different EST conditions. Methods: Western blot analysis and ELISA were used to determine the protein expression of autophagy and Nrf2-ARE pathways; and the levels of pro-inflammatory cytokines (PICs) and a key marker of oxidative stress. Results: Lacking of EST amplifies autophagy and attenuates Nrf2-ARE pathway in the hippocampus CA1 region. Blocking autophagy alleviates neurological deficits following cerebral ischemia with lacking of EST levels and the effects of autophagy are associated with PIC and oxidative stress. Conclusions: EST influences the protein expression of autophagy and Nrf2-ARE signaling in the brain, which is linked to the pathophysiological processes of PICs and oxidative stress. Moreover, inhibition of autophagy plays a beneficial role in modulating neurological deficits after cerebral ischemia observed under conditions of a lower level of EST.

\section{Introduction}

The major gonadal sex hormone, estradiol (EST), plays potent neurotrophic and neuroprotective roles in immature and adult brain [1]. In particular, clinical studies have shown that EST reduces the risk of stroke and decreases the incidence and progression of the disease [2-4]. EST also inhibits cell death that occurs in response to a variety of neuronal stimuli, including pro-inflammation and oxidative stress $[1,5]$. Nevertheless, it is necessary to have a better understanding of the cellular mechanisms responsible for EST in involvement of cerebral ischemia. 


\section{Cellular Physiology Cell Physiol Biochem 2017;41:2027-2036 \begin{tabular}{l|l} 
DOI: 10.1159/000475433 & Ond Biochemistry \\
Published online: AprIII3, 2017 & $\begin{array}{l}\text { 2017 The Author(s). Published by S. Karger AG, Basel } \\
\text { www.karger.com/cpb }\end{array}$
\end{tabular} \\ Li et al.: Female Sex Hormones and Cerebral Ischemia}

As an alternative cell death programs, autophagy is considered as an important nonapoptotic cell death pathway [6,7]. It is a cellular catabolic process that contributes to quality control and maintenance of the cellular energetic balance through the turnover of protein and organelles in lysosomes. Induction of autophagy recruits proteins and lipids from different intracellular membranes that sequester cytoplasmic material and deliver it through vesicular fusion to lysosomes for degradation [8]. Autophagy occurs constitutively at a basal level, but can also be induced by both physiological and pathological stimuli. As autophagy can be stimulated in both adult and neonatal animals, it has been suggested to contribute to ischemic neuronal injury [9]. However, the role of autophagy as a mediator of cell death is controversial. Some studies have shown that autophagy contributes to ischemic tissue injury [10-13], whereas others have shown that the induction of autophagy plays a protective role and improves neuronal cell death [14].

Specifically, the previous studies demonstrated that autophagy signal is engaged in protecting cell death caused by ischemic brain injury $[11,15,16]$; however, there is lacking of evidence showing that female sex hormones such as EST influences on autophagy signal. Therefore, in the current study we examined autophagy signal pathways in the hippocampus regions of control mice with lacking of EST and mice with EST replacement. We also determined the involvement of pro-inflammatory cytokines (PICs) and oxidative stress in autophagy signal as EST was lacking. In addition, we determined the effects of blocking autophagy on neurological deficits following cerebral ischemia with different EST levels.

Nuclearfactor (erythroid-derived2)-like2 (Nrf2, also known as NFE2L2) is a transcription factor and as a basic leucine zipper protein it regulates the expression of antioxidant proteins that protect against oxidative damage triggered by injury and inflammation [17]. Numerous drugs that stimulate the Nrf2 pathway have been studied for treatment of diseases that are caused by oxidative stress [18]. Under normal or unstressed conditions, Nrf2 is kept in the cytoplasm by a cluster of proteins that degrade it quickly [19-21]. Under oxidative stress, Nrf2 is not degraded, but instead travels to the nucleus where it binds to a DNA promoter and initiates transcription of anti-oxidative genes and their proteins [19-21]. In the nucleus, it combines (forms a heterodimer) with a small Maf protein and binds to the antioxidant response element (ARE) in the upstream promoter region of many anti-oxidative genes, and initiates their transcription [21]. Thus, in this study we further examined the engagement of Nrf2-ARE pathway in the hippocampus regions of control mice with lacking of EST and mice with EST replacement.

We hypothesized that lacking of EST upregulates representative autophagy signal including Atg5, LC3 (cytosolic LC3 and autophagosomes bound part of LC3) and Beclin 1 and decreases the levels of p62 protein [also called sequestosome 1 [(SQSTM1), a maker of autophagic flux], and attenuates expression of Nrf2 and Nrf2-regulated NADPH quinone oxidoreductase-1 (NQO1) in the hippocampus regions. We further hypothesized that blocking autophagy alleviates neurological deficits following cerebral ischemia with lacking of EST levels and the effects of autophagy are associated with PICs and oxidative stress.

\section{Materials and Methods}

\section{Animals}

All experimental procedures were in accordance with the guidelines of the International Association for the Study of Pain and were approved by the Animal Research Committee of our medical institution. A total of one hundred twenty female C57BL/6 mice (12-15 weeks old) were used in this study. Under isoflurane anesthesia, a sham operation or bilateral ovariectomy was performed. A week after the surgery, the ovariectomized mice received subcutaneous implantation of a placebo or pellets (Innovative Res., Sarasota, FL) containing sex hormone releasing over a 21-day period [22]. In additional group, ovariectomized mice received injection of 3-methyladenine (3-MA, $15 \mathrm{mg} / \mathrm{kg} /$ day, i.p.). Accordingly, the mice were divided into four groups: sham control $(n=16)$; placebo (PBO, $n=15)$; treatment of 17 $\beta$-EST (EST: $0.05 \mathrm{mg}, \mathrm{n}=15)$; and treatment of 3-MA (3-MA, n=19). 


\section{Cellular Physiology Cell Physiol Biochem 2017;41:2027-2036 \begin{tabular}{l|l} 
and Biochemistry Published online: April 13, 2017 & $\begin{array}{l}\text { (c) } 2017 \text { The Author(s). Published by S. Karger AG, Basel } \\
\text { www.karger.com/cpb }\end{array}$
\end{tabular}}

Li et al.: Female Sex Hormones and Cerebral Ischemia

\section{Determination of treatment effectiveness}

In order to confirm the effectiveness of treatment, the levels of serum estrogen were measured at the end of 3 week-treatment (sham, PBO and EST; $n=5$ in each group). Briefly, the animals were anesthetized with an overdose of isoflurane, and blood was collected from the ophthalmic artery. Serum estradiol levels were measured using an EIA kit (Cayman Chemical, Ann Arbor, MI).

In addition, a vaginal smear was made on a glass slide in all animals. After drying the smear, slides were stained and analyzed for different phases of estrous cycle according to proportions of epithelial cells, cornified cells and leukocytes present in the smear. The smear in the ovariectomized mice showed typical patterns according to the hormone intervention. The mice who failed to show the estrous cycle stages were not included in this study.

\section{Cerebral ischemia}

In a subset of experiments, middle cerebral artery occlusion was performed in PBO and EST mice with and without administration of 3-MA. The mice were divided into four groups: PBO + ischemia (n=12); PBO + ischemia + 3-MA (n=10); EST + ischemia $(n=8)$; and EST + ischemia + 3-MA ( $n=10)$. Cerebral blood flow was monitored using laser Doppler flowmetry (PeriFlux 5000; Sweden). During surgery, an occlusion was considered to be successful when blood flow declined to less than $15 \%$ of the pre-ischemic baseline level; otherwise, the animals were discarded. Following 1 hour of transient occlusion, cerebral blood flow was restored by removing the nylon suture for 24 hours.

\section{Western blot analysis}

To examine expression of autophagy and Nrf2-ARE pathways, the hippocampal tissues were processed using a standard Western Blot procedure. Briefly, total protein was extracted by homogenizing the hippocampal samples in ice-cold immunoprecipitation assay buffer. The lysates were centrifuged and the supernatants were collected for measurements of protein concentrations using a BCA reagent. After being denatured by heating at $95^{\circ} \mathrm{C}$ for $5 \mathrm{~min}$ in buffer, the supernatant samples containing $20 \mu \mathrm{g}$ of protein were loaded onto 4-20\% Mini-PROTEAN TGX gels and electrically transferred to a polyvinylidene fluoride membrane. The membrane was blocked in 5\% nonfat milk in $0.1 \%$ Tween-TBS buffer and was incubated overnight with respective primary antibodies (rabbit anti-Atg5; anti-LC3/B; anti-Beclin 1; anti-p62/ SQSTM1; anti-Nrf2 and anti-NQ01, 1:250). Next, the membranes were washed and incubated with an alkaline phosphatase conjugated anti-rabbit secondary antibody (1:500). All antibodies were obtained from the Abcam Co. or Santa Cruz Biotech. The immunoreactive proteins were detected by enhanced chemiluminescence system. The bands recognized by the primary antibody were visualized by exposure of the membrane onto an $\mathrm{x}$-ray film. The membrane was stripped and incubated with mouse anti- $\beta$-actin to show equal loading of the protein. Then, the film was scanned and the optical density of each protein as well as $\beta$-actin bands was analyzed using the Scion Image software. The values for densities of immunoreactive band $/ \beta$-actin band from the same lane were determined. Each of the values was then normalized to a control sample.

\section{ELISA}

The levels of IL-1 $\beta$, IL- 6 and TNF- $\alpha$ were determined using an ELISA assay kit (Promega Corp. Madison, WI) according to the provided description and modification. Briefly, polystyrene 96-well microtitel immunoplates were coated with respective affinity-purified rabbit anti-IL-1 $\beta$, anti-IL- 6 and anti-TNF- $\alpha$ antibodies. Parallel wells were coated with purified rabbit IgG for evaluation of nonspecific signal. After overnight incubation at room temperature and 2 hours of incubation with the coating buffer containing $50 \mathrm{mM}$ carbonate buffer ( $\mathrm{pH} 9.5$ ) in $2 \%$ BSA, the plate were washed with $50 \mathrm{mM}$ Tris- $\mathrm{HCl}$. After extensive washing, the diluted samples and IL-1 $\beta$, IL- 6 and TNF- $\alpha$ standard solution were distributed in each plate, respectively, and left at room temperature overnight. The plates were then washed and incubated with their respective anti-galactosidase per well. Then, the plates were washed and incubated with substrate solution. After an incubation of 2 hours at $37^{\circ} \mathrm{C}$, the optical density was measured by using an ELISA reader.

The similar method was used to examine the levels of 8-isoprostaglandin F2 $\alpha$ (8-iso PGF2 $\alpha$, a reactive oxygen species production as an indicator of oxidative stress) in the hippocampal CA1 region following the manufacturer's instructions [commercially available enzyme immunoassay kit (8-iso PGF2 $\alpha$, Cayman Chemical Co.]. 
Neurological function and brain edema

The modified method of Neurological Severity Score (mNSS) was used to examine neurological functions in this study. It is noted that mNSS was generally used to assess a combination of motor, sensory, and balance functions [23]. Neurological function was graded on a scale of 0-18 (normal score, 0; maximal deficit score, 18). If we found that mNSS score of rats was $>0$ before cerebral ischemia, this indicated that the animals were abnormal and they were excluded from the experiment.

Brain edema (brain water content) was determined 24 hours after cerebral ischemia. The brain slices ( $2 \mathrm{~mm}$ thick) of the hemispheres and cerebellum were cut. The whole brain water content was calculated from all slices. The brain slices were weighed to obtain the wet weight immediately and dried in an oven at $100 \mathrm{C} \circ$ for 24 hours to obtain the dry weight. The cerebellum was used as the internal control. The water content was expressed as the following formula: [(wet weight) - (dry weight)]/(wet weight) $\times 100 \%$.

\section{Statistical analysis}

All data were analyzed using a two-way repeated-measures analysis of variance. Values are presented as means \pm SEM. For all analyses, differences were considered significant at $P<0.05$. All statistical analyses were performed by using SPSS for Windows version 11.0.

\section{Results}

\section{Levels of serum estrogen}

First, serum estrogen levels were measured to confirm the efficacy of EST replacement. The serum estrogen levels were $8.9 \pm 1.5 \mathrm{pg} / \mathrm{ml}$ in the ovariectomized mice and $23.5 \pm 3.1 \mathrm{pg} /$ $\mathrm{ml}$ in the sham control mice ( $P<0.05$, control $v s$. ovariectomized group; $\mathrm{n}=5$ in each group). The serum estrogen levels were $27.7 \pm 4.2 \mathrm{pg} / \mathrm{ml}$ in mice with replacement of EST ( $\mathrm{n}=5$; $P<0.05 v s$. ovariectomized group). There were no significant differences in estrogen levels between control group and EST group $(P>0.05)$.

Fig. 1. Protein expression levels of autophagy and Nrf2-ARE signal. (A). Top panel and bottom panel are representative bands and averaged data: increases of Atg5, LC3 (bands I \&II) and Beclin 1 in the hippocampus CA1 region of $\mathrm{PBO}$ mice and replacement of EST attenuated upregulation of autophagy. It is also noted that SQSTM1, a protein selectively degraded by autophagy was decreased in the hippocampus CA1 region of PBO mice. Nrf2 and Nrf2-regulated NQ01 were decreased in the CA1 region of PBO mice and EST can restore impaired Nrf2 and NQ01. ${ }^{*} P<0.05$, PBO vs. control and EST replacement. $\mathrm{N}=6$ in control; 8 in PBO group and 8 in EST group. (B). Top panel and bottom panel are representative bands and averaged data: 3-MA effectively attenuated LC3 (bands I \&II) expression in the CA1 of mice with no significant effects on Nrf2. ${ }^{*} P<0.05$, PBO vs. control and 3-MA for LC3-I and LC-II; and $v$ s. control for $\mathrm{Nrf2}$. $\mathrm{N}=10$ in mice injected with 3-MA.

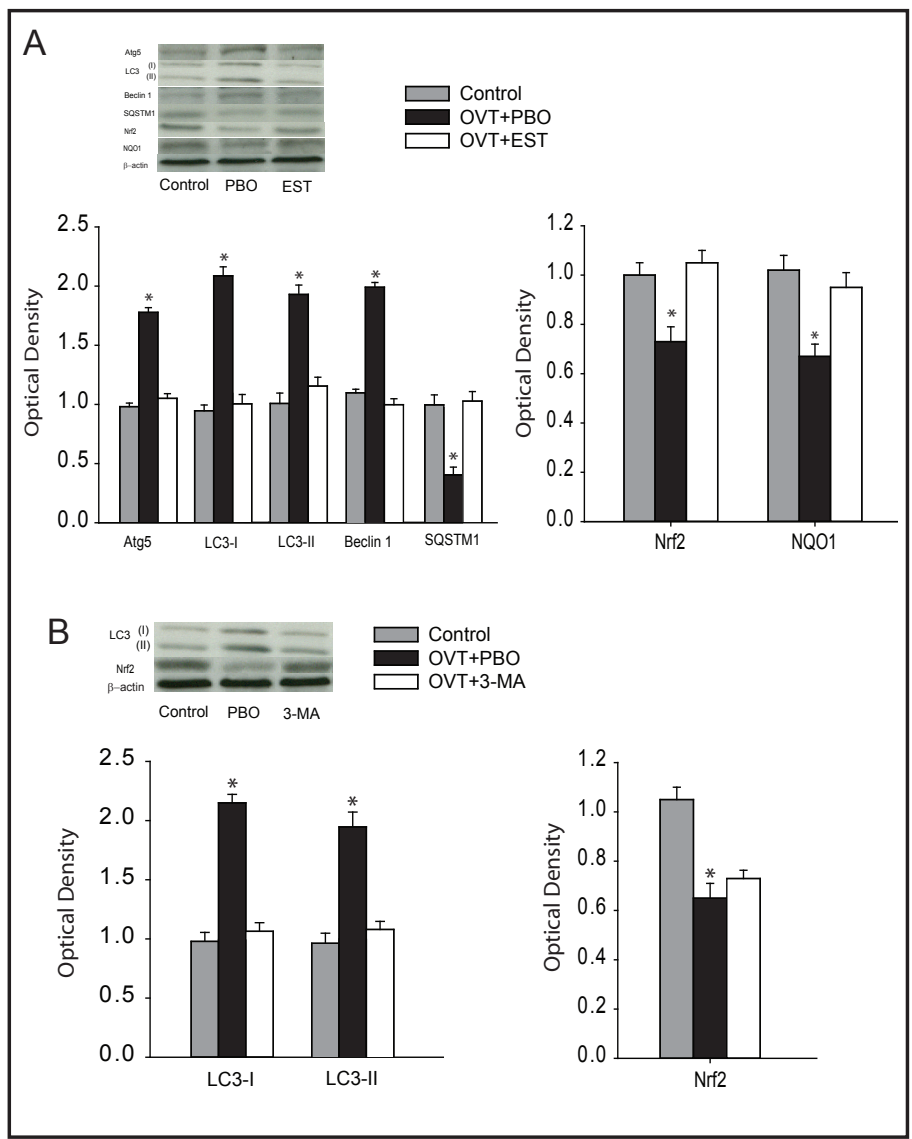


Fig. 2. Levels of PICs and 8-iso PGF $2 \alpha$. IL-1 $\beta$, IL-6, TNF- $\alpha$ and 8 -iso PGF2 $\alpha$ were increased in the hippocampus CA1 of PBO mice as compared with control mice and EST can attenuate upregulation of PICs and 8-iso PGF2 $\alpha$. Administration of 3-MA also significantly attenuated amplification of PICs and PGF2 $\alpha$ induced by lacking of EST. ${ }^{*} P<0.05$, PBO vs. control, EST replacement and 3-MA injection. $\mathrm{N}=16$ in control; 15 in PBO; 15 in EST and 19 in 3-MA.

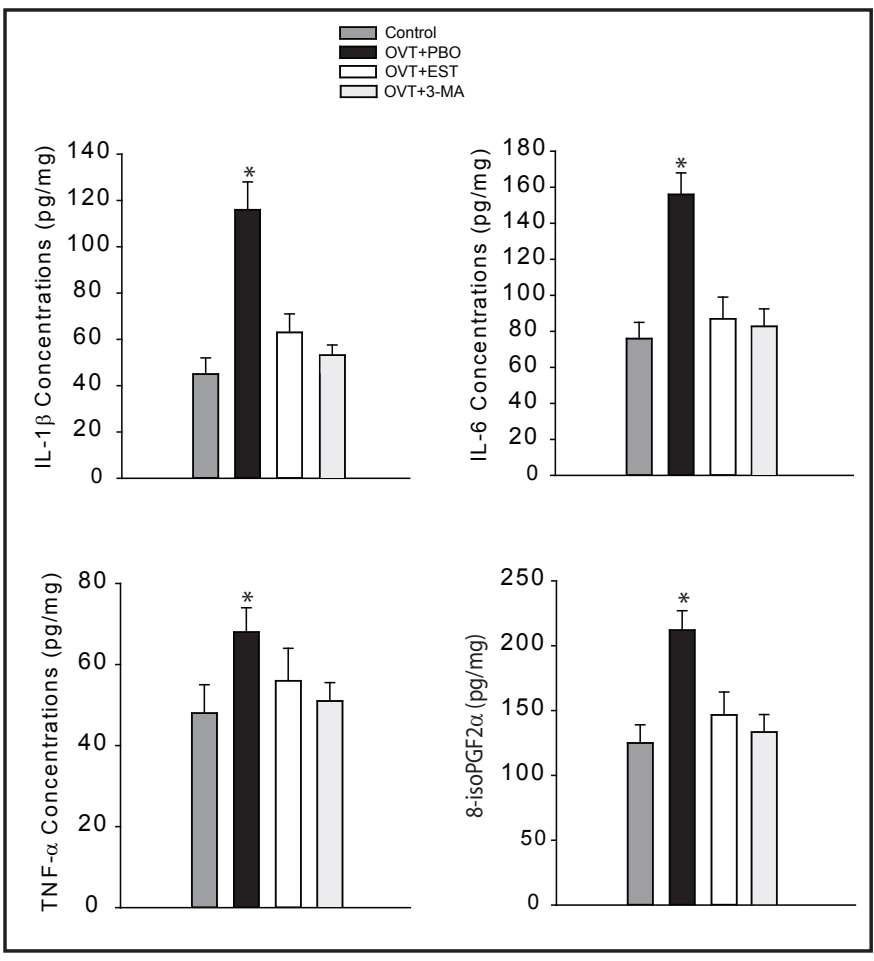

Expression of autophagy in PBO mice and EST mice

Figure 1 illustrates the protein expression of representative autophagy, including Atg5, LC3, Beclin 1 and SQSTM1. Atg5, LC3 and Beclin 1 were upregulated; whereas SQSTM1 was decreased in the hippocampus CA1 region of $\mathrm{PBO}$ mice as compared with control animals $(P<0.05$, control vs. $\mathrm{PBO}$ groups; $\mathrm{n}=6$ in control and $\mathrm{n}=8$ in $\mathrm{PBO}$ group). This figure also demonstrates that replacement of EST significantly attenuated the amplified autophagy $(P<0.05$, PBO vs. EST groups; $n=8$ in EST group). In contrast, Figure 1 further shows that the protein expression levels of Nrf2 and NQO1 were decreased in the CA1 region of PBO mice and EST can restore impaired Nrf2-ARE pathway $(P<0.05$, PBO mice vs. control and EST replacement; $n=6-8$ ). In order to determine effectiveness of 3-MA, we further examined expression of LC3 as well as Nrf2 in the CA1 of mice with lacking of EST that were injected with 3-MA $(n=10)$, demonstrating that 3-MA significantly attenuated LC3, but failed to alter Nrf2.

PICs and 8-iso PGF2 $\alpha$ in PBO mice and EST mice

Figure 2 demonstrates that IL-1 $\beta$, IL- 6 and TNF- $\alpha$ were increased in the hippocampus CA1 of PBO mice $(P<0.05$ vs. control; $\mathrm{n}=16$ in control and $\mathrm{n}=15$ in PBO group). Likewise, 8-iso PGF2 $\alpha$ was also increased in the hippocampus of PBO mice $(P<0.05$ vs. control, $\mathrm{n}=16$ in control and $n=15$ in PBO mice). It is noted that replacement of EST significantly attenuated increases of PICs and 8-iso PGF $2 \alpha(P<0.05 v s$. PBO mice; $\mathrm{n}=15$ in each of PBO and EST groups). There were no significant difference observed in the levels of PICs and 8-iso PGF2 $\alpha$ between control group and EST group $(P>0.05)$. In addition, administration of 3-MA significantly attenuated amplification of IL-1 $\beta$, IL-6, TNF- $\alpha$ and 8 -iso PGF $2 \alpha$ induced by lacking EST ( $P$ $<0.05$ vs. PBO mice; $\mathrm{n}=19$ in 3-MA group).

Effects of 3-MA on autophagy and Nrf2 signal, and neurological function and brain edema after cerebral ischemia

Figure 3A \& B show that cerebral ischemia increased Atg5 and decreased SQSTM1 in the hippocampus CA1 region of $\mathrm{PBO}$ mice and EST mice $(P<0.05$ vs. control). It is noted that the effects of ischemia were observed to be a less degree in EST mice $(P<0.05$ vs. PBO mice). As 
Fig. 3. (A \& B). Cerebral ischemia increased Atg5 and decreased SQSTM1 in the hippocampus CA1 region of $\mathrm{PBO}$ mice and EST mice. As 3-MA was given, the changes of Atg5 and SQSTM1 were attenuated. Likewise, Nrf2 and NQ01 were decreased in the CA1 region of PBO mice and EST mice after ischemia, but 3-MA did not significantly alter impaired Nrf2 and NQO1. Top panel and bottom panel are representative bands and averaged data. ${ }^{*} P<0.05$, PBO vs. control. $\# P<0.05$, no treatment $v s$. 3-MA treatment in $\mathrm{PBO}$ mice and EST mice. $\mathrm{N}=5$ 8 in each group. (C). Left panel shows an increase in mNSS in PBO mice after cerebral ischemia and that the increase was less in EST animals. This panel

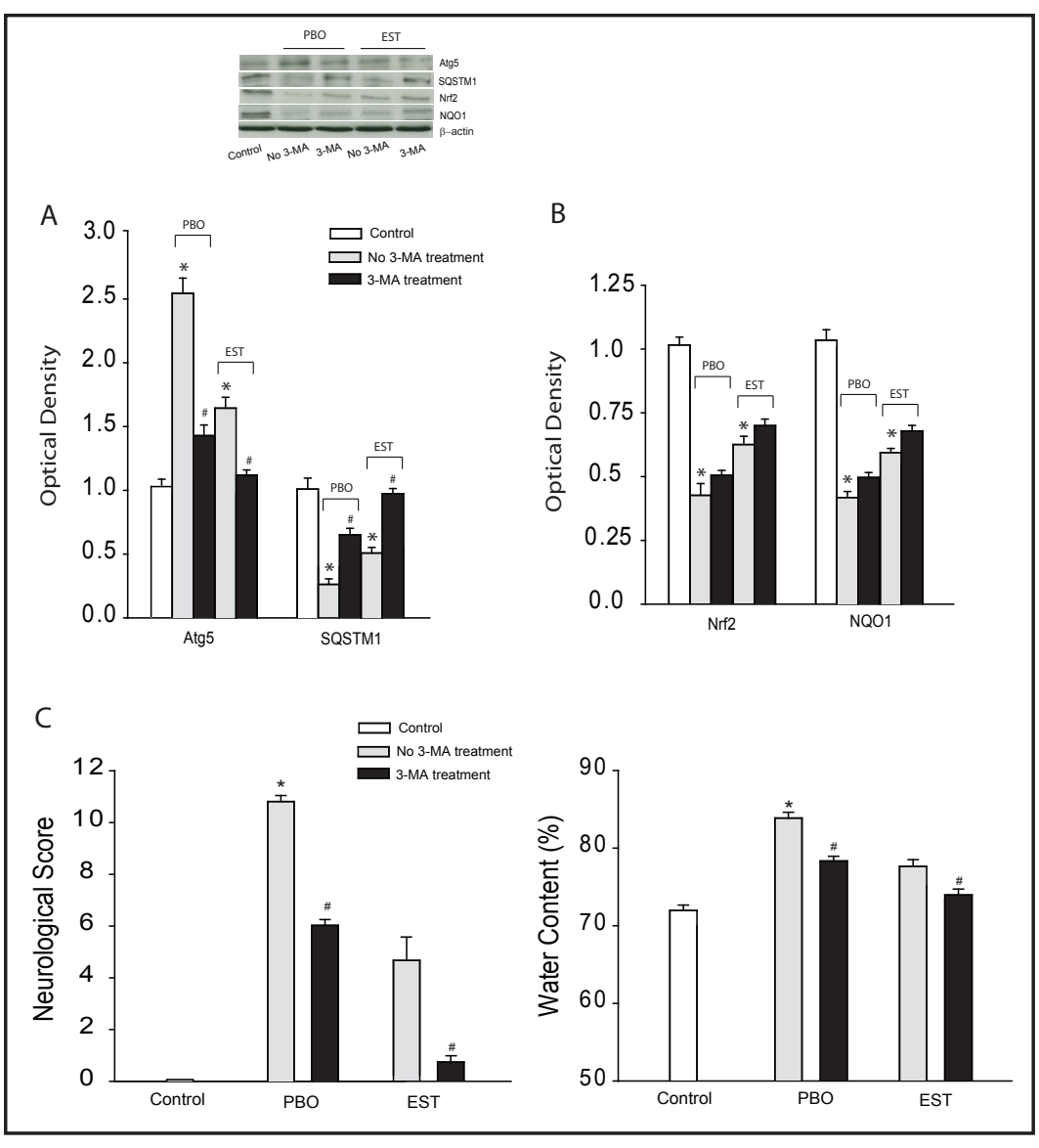
also shows that 3-MA significantly attenuated an increase in mNSS in PBO mice and EST mice. Likewise, right panel shows that increased water content was smaller in EST mice and that 3-MA can attenuate increased water content in PBO mice and EST mice. ${ }^{*} P<0.05$ vs. control mice $(\mathrm{n}=16)$ and EST mice $(\mathrm{n}=8) ; \# P<0.05$, no treatment vs. 3-MA in PBO mice and EST mice. There was no significant difference in mNSS and water content between control and EST group with 3-MA $(n=10)$.

3-MA was given, the changes of Atg5 and SQSTM1 were attenuated $(P<0.05$, 3-MA treatment vs. no treatment in PBO mice and EST mice). Likewise, Nrf2 and NQO1 were decreased in the CA1 region of PBO mice and EST mice after ischemia, but 3-MA failed to significantly alter impaired Nrf2 and NQO1.

Figure 3C (left panel) shows that cerebral ischemia increased the mNSS in PBO mice $(P<0.05$ vs. control mice; $n=16$ in control and $n=12$ in PBO group). This figure further demonstrates that 3-MA significantly attenuated the impaired mNSS in animals following cerebral ischemia $(P<0.05$, ischemic mice with no treatment $v s$. ischemia mice with 3-MA; $\mathrm{n}=10$ in ischemic group with 3-MA). Likewise, Figure 3 (right panel) shows that ischemia amplified water content of brain tissues in PBO mice and administration of 3-MA significantly attenuated increases of water content. In addition, cerebral ischemia elevated the mNSS and water content to a smaller degree in EST mice and the effects were significantly attenuated by 3 -MA $(P<0.05$, vs. EST ischemic mice with no treatment; $n=8$ without $3-M A$; and $n=10$ with injection of 3-MA).

\section{Discussion}

Ischemic stroke is a consequence of vascular occlusion [24]. The result is irreversible neural tissue injury, which is a major cause of death and disability worldwide [25]. As the 
world's population continues to age, the incidence of stroke is expected to grow, increasing the interest and need for novel approaches focused on improving the recovery and quality of life of stroke patients $[24,25]$. Thus, it is necessary to have a better understanding of the cellular and molecular mechanisms responsible for cerebral ischemia.

Clinical and experimental studies have suggested that a risk of stroke varies in male and female individuals [26-28]. Although the estrogen treatment of stroke is under debate, a decrease in ischemic brain damages is seen in adult female as compared with male in many models of induced global and focal cerebral ischemia [27] likely due to the levels of sex hormones. Though there are many mechanisms by which female sex hormones are involved in ischemic brain injuries [29], there is lacking evidence showing a relation between female sex hormones and autophagy being involved in ischemic conditions. The purpose of the current study was to examine the effects of female sex hormones, namely EST on the protein expression levels of main autophagy indicators such as Atg5, cytosolic LC3 and autophagosomes bound part of LC3 and Beclin 1 in the hippocampal CA1 area. We also examined the role played by EST in regulating Nrf2-ARE signal pathway. We further determined if blocking autophagy can alter cerebral pro-inflammatory IL- $1 \beta$, IL- 6 and TNF- $\alpha$, and a reactive oxygen species production, 8-iso PGF $2 \alpha$. Overall, data of this study showed that lack of EST upregulates Atg5, LC3 and Beclin 1 and attenuates Nrf2 and Nrf2-regulated NQ01 in the brain likely linking to exaggerated PICs and oxidative stress. Replacement of EST and/or blocking autophagy attenuates neurological deficits observed in ischemic mice likely via PIC and oxidative mechanisms.

In addition, our results further demonstrated that the changes of p62/SQSTM1, which is a protein selectively degraded by autophagy as a marker of the autophagy flux, were consistent with changes of representative autophagy. This specifically indicates that autophagy flux is engaged in the pathophysiological process when EST is lacking.

Moreover, we examined the effects of administration of 3-MA on representative autophagy Atg5 and Nrf2 signal, and neurological function and brain edema in PBO mice and EST mice after cerebral ischemia. Our data demonstrated that ischemia upregulated autophagy signal and downregulated Nrf2 signal and the effects appeared to be a greater degree in PBO mice. As 3-MA was given, increased expression of autophagy, worsened neurological function and brain edema induced by ischemia were largely improved. This is evidenced that autophagy is engaged in cerebral ischemia with lacking of EST. It is noted that Nrf2-ARE signal was not significantly altered by 3-MA, suggesting that its effects are likely independent of autophagy following cerebral ischemia.

A limitation of this study should be noted that we did not determine the direct effects of Nrf2 signal on neurological score in ischemic mice. Nonetheless, we observed that lack of EST attenuated Nrf2-ARE signal and replacement of EST can largely restore the protein expression levels of Nrf2 in the hippocampus and this treatment also improved neurological score in ischemic mice.

In general, certain cerebrovascular-related pathologies coincide with changes in circulating ovarian hormones in women, e.g., menstrual migraine and increased stroke risk postpartum and after menopause [30-32]. The influence of female sex hormones on the cerebral vasculature has important implications for a variety of disorders, in particular ischemic brain injury such as stroke [33-37].

Specifically, estrogen has vascular and neuroprotective effects, in part, by improving blood flow during and after an ischemic insult [27, 30]. Estrogen treatment has also been shown to suppress a formation of experimental cerebral aneurysms [38, 39]. Estrogen enhances protective endothelial mechanisms with decreasing cerebrovascular inflammation and reactive oxygen species production. Nevertheless, the multiple mechanisms are responsible for the protecting effects of estrogen, including eNOS and inflammation etc. $[27,30]$. In ovariectomized female animals, EST treatment significantly reduces the infarct volume and improves neuronal dysfunction after focal ischemia and EST inhibits neuronal cells death that occurs in response to oxidative stress and excitotoxic amino acids [40, 41]. Consistent with this notion, results of our current study further suggest that PICs and 


\section{Cellular Physiology Cell Physiol Biochem 2017;41:2027-2036

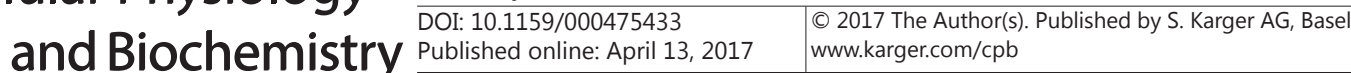 \\ \begin{tabular}{ll} 
Published online: April 13, $2017 \quad$ www.karger.com/cpb \\
\hline
\end{tabular}}

oxidative stress are engaged in the role played by EST and autophagy in regulating brain ischemic injuries.

Nrf2-ARE signal pathway has been considered to play a role in regulating the expression of antioxidant proteins thereby protecting against oxidative damage triggered by injury and inflammation [17]. In the present study, our data show that lacking of EST impairs the protein expression levels of Nrf2 and Nrf2-regulated NQO1 in the hippocampus. It was observed that Nrf2 is not significantly altered by blocking autophagy although PICs and reactive oxygen species production are effectively attenuated in the brain. This indicates that protective mechanisms by Nrf2-ARE are independent of autophagy following cerebral ischemia. Nevertheless, we found that EST replacement can restore impaired levels of Nrf2 and NQ01. Thus, activation of Nrf2-ARE pathway is implicated for benefits to ischemic brain diseases that are associated with inflammation and oxidative stress [18].

\section{Conclusions}

Overall, circulating EST influences expression levels of autophagy and Nrf2-ARE signal pathway in the hippocampal CA1 region. Lacking of EST exaggerates PICs and oxidative stress and neurological deficits observed in mice after cerebral ischemia. Notably, inhibition of autophagy plays a beneficial role in modulating neurological deficits induced by cerebral ischemia under conditions of a lower level of EST, which is linked to the pathophysiological processes of pro-inflammation and oxidative stress.

\section{Disclosure Statement}

No conflict of interest declared.

\section{References}

1 Brann DW, Dhandapani K, Wakade C, Mahesh VB, Khan MM: Neurotrophic and neuroprotective actions of estrogen: basic mechanisms and clinical implications. Steroids 2007;72:381-405.

- Schierbeck LL, Rejnmark L, Tofteng CL, Stilgren L, Eiken P, Mosekilde L, Kober L, Jensen JE: Effect of hormone replacement therapy on cardiovascular events in recently postmenopausal women: randomised trial. Bmj 2012;345:e6409.

3 Smith NL, Blondon M, Wiggins KL, Harrington LB, van Hylckama Vlieg A, Floyd JS, Hwang M, Bis JC, McKnight B, Rice KM, Lumley T, Rosendaal FR, Heckbert SR, Psaty BM: Lower risk of cardiovascular events in postmenopausal women taking oral estradiol compared with oral conjugated equine estrogens. JAMA Intern Med 2014;174:25-31.

4 Xu Z, Li Y, Tang S, Huang X, Chen T: Current use of oral contraceptives and the risk of first-ever ischemic stroke: A meta-analysis of observational studies. Thromb Res 2015;136:52-60.

-5 Strom JO, Theodorsson A, Theodorsson E: Mechanisms of estrogens' dose-dependent neuroprotective and neurodamaging effects in experimental models of cerebral ischemia. Int J Mol Sci 2011;12:1533-1562.

-6 Blumberg RM, Cady EB, Wigglesworth JS, McKenzie JE, Edwards AD: Relation between delayed impairment of cerebral energy metabolism and infarction following transient focal hypoxia-ischaemia in the developing brain. Exp Brain Res 1997;113:130-137.

7 Edinger AL, Thompson CB: Death by design: apoptosis, necrosis and autophagy. Curr Opin Cell Biol 2004;16:663-669.

8 Hamasaki M, Shibutani ST, Yoshimori T: Up-to-date membrane biogenesis in the autophagosome formation. Curr Opin Cell Biol 2013;25:455-460.

9 Northington FJ, Chavez-Valdez R, Martin LJ: Neuronal cell death in neonatal hypoxia-ischemia. Ann Neurol 2011;69:743-758. 


\section{Cellular Physiology Cell Physiol Biochem 2017;41:2027-2036 \begin{tabular}{ll|l} 
and Biochemistry & $\begin{array}{l}\text { DOI: 10.1159/000475433 } \\
\text { Published online: April 13, } 2017\end{array}$ & $\begin{array}{l}\text { @ } 2017 \text { The Author(s). Published by S. Karger AG, Basel } \\
\text { www.karger.com/cpb }\end{array}$ \\
\hline
\end{tabular}}

10 Ginet V, Puyal J, Clarke PG, Truttmann AC: Enhancement of autophagic flux after neonatal cerebral hypoxiaischemia and its region-specific relationship to apoptotic mechanisms. Am J Pathol 2009;175:1962-1974.

11 Koike M, Shibata M, Tadakoshi M, Gotoh K, Komatsu M, Waguri S, Kawahara N, Kuida K, Nagata S, Kominami E, Tanaka K, Uchiyama Y: Inhibition of autophagy prevents hippocampal pyramidal neuron death after hypoxic-ischemic injury. Am J Pathol 2008;172:454-469.

12 Hsieh DJ, Kuo WW, Lai YP, Shibu MA, Shen CY, Pai P, Yeh YL, Lin JY, Viswanadha VP, Huang CY: 17betaEstradiol and/or Estrogen Receptor beta Attenuate the Autophagic and Apoptotic Effects Induced by Prolonged Hypoxia Through HIF-1alpha-Mediated BNIP3 and IGFBP-3 Signaling Blockage. Cell Physiol Biochem 2015;36:274-284.

-13 Zhu T, Yao Q, Wang W, Yao H, Chao J: iNOS Induces Vascular Endothelial Cell Migration and Apoptosis Via Autophagy in Ischemia/Reperfusion Injury. Cell Physiol Biochem 2016;38:1575-1588.

14 Papadakis M, Hadley G, Xilouri M, Hoyte LC, Nagel S, McMenamin MM, Tsaknakis G, Watt SM, Drakesmith CW, Chen R, Wood MJ, Zhao Z, Kessler B, Vekrellis K, Buchan AM: Tsc1 (hamartin) confers neuroprotection against ischemia by inducing autophagy. Nat Med 2013;19:351-357.

15 Lu Q Harris VA, Kumar S, Mansour HM, Black SM: Autophagy in neonatal hypoxia ischemic brain is associated with oxidative stress. Redox Biol 2015;6:516-523.

16 Wei K, Wang P, Miao CY: A double-edged sword with therapeutic potential: an updated role of autophagy in ischemic cerebral injury. CNS Neurosci Ther 2012;18:879-886.

17 Moi P, Chan K, Asunis I, Cao A, Kan YW: Isolation of NF-E2-related factor 2 (Nrf2), a NF-E2-like basic leucine zipper transcriptional activator that binds to the tandem NF-E2/AP1 repeat of the beta-globin locus control region. Proc Natl Acad Sci U S A 1994;91:9926-9930.

$>18$ Gold R, Kappos L, Arnold DL, Bar-Or A, Giovannoni G, Selmaj K, Tornatore C, Sweetser MT, Yang M, Sheikh SI, Dawson KT: Placebo-controlled phase 3 study of oral BG-12 for relapsing multiple sclerosis. N Engl J Med 2012;367:1098-1107.

-19 Itoh K, Chiba T, Takahashi S, Ishii T, Igarashi K, Katoh Y, Oyake T, Hayashi N, Satoh K, Hatayama I, Yamamoto M, Nabeshima Y: An Nrf2/small Maf heterodimer mediates the induction of phase II detoxifying enzyme genes through antioxidant response elements. Biochem Biophys Res Commun 1997;236:313-322.

-20 Sekhar KR, Rachakonda G, Freeman ML: Cysteine-based regulation of the CUL3 adaptor protein Keap1. Toxicol Appl Pharmacol 2010;244:21-26.

-21 Yamamoto T, Suzuki T, Kobayashi A, Wakabayashi J, Maher J, Motohashi H, Yamamoto M: Physiological significance of reactive cysteine residues of Keap1 in determining Nrf2 activity. Mol Cell Biol 2008;28:2758-2770.

22 Gupta S, Villalon CM, Mehrotra S, de Vries R, Garrelds IM, Saxena PR, MaassenVanDenbrink A: Female sex hormones and rat dural vasodilatation to CGRP, periarterial electrical stimulation and capsaicin. Headache 2007;47:225-235.

23 Zhang Y, Yi B, Ma J, Zhang L, Zhang H, Yang Y, Dai Y: Quercetin promotes neuronal and behavioral recovery by suppressing inflammatory response and apoptosis in a rat model of intracerebral hemorrhage.

Neurochem Res 2015;40:195-203.

-24 Donnan GA, Fisher M, Macleod M, Davis SM: Stroke. Lancet 2008;371:1612-1623.

25 Deb P, Sharma S, Hassan KM: Pathophysiologic mechanisms of acute ischemic stroke: An overview with emphasis on therapeutic significance beyond thrombolysis. Pathophysiology 2010;17:197-218.

26 Cheng Y, Su Q, Shao B, Cheng J, Wang H, Wang L, Lin Z, Ruan L, ZhuGe Q, Jin K: 17 beta -Estradiol attenuates poststroke depression and increases neurogenesis in female ovariectomized rats. Biomed Res Int 2013;2013:392434.

27 Koellhoffer EC, McCullough LD: The effects of estrogen in ischemic stroke. Transl Stroke Res 2013;4:390401.

28 Koh PO: Estradiol ameliorates the reduction in parvalbumin expression induced by ischemic brain injury. Neurosci Lett 2014;574:36-40.

29 Ma Y, Guo H, Zhang L, Tao L, Yin A, Liu Z, Li Y, Dong H, Xiong L, Hou W: Estrogen replacement therapyinduced neuroprotection against brain ischemia-reperfusion injury involves the activation of astrocytes via estrogen receptor beta. Sci Rep 2016;6:21467.

-30 Brass LM: Hormone replacement therapy and stroke: clinical trials review. Stroke 2004;35:2644-2647.

31 Cipolla MJ, Vitullo L, McKinnon J: Cerebral artery reactivity changes during pregnancy and the postpartum period: a role in eclampsia? Am J Physiol Heart Circ Physiol 2004;286:H2127-2132. 


\section{Cellular Physiology Cell Physiol Biochem 2017;41:2027-2036 \begin{tabular}{l|l} 
DOI: 10.1159/000475433 & Ond Biochemistry Published 2017 The Author(s). Published by S. Karger AG, Basel \\
www.karger.com/cpb
\end{tabular} \\ Li et al.: Female Sex Hormones and Cerebral Ischemia}

32 Marcus DA: Sex hormones and chronic headache in women. Expert Opin Pharmacother 2001;2:1839-1848.

33 Green PS, Yang SH, Nilsson KR, Kumar AS, Covey DF, Simpkins JW: The nonfeminizing enantiomer of 17beta-estradiol exerts protective effects in neuronal cultures and a rat model of cerebral ischemia. Endocrinology 2001;142:400-406.

34 Perrella J, Bhavnani BR: Protection of cortical cells by equine estrogens against glutamate-induced excitotoxicity is mediated through a calcium independent mechanism. BMC Neurosci 2005;6:34.

-35 Wang J, Green PS, Simpkins JW: Estradiol protects against ATP depletion, mitochondrial membrane potential decline and the generation of reactive oxygen species induced by 3-nitroproprionic acid in SK-NSH human neuroblastoma cells. J Neurochem 2001;77:804-811.

36 Wang X, Dykens JA, Perez E, Liu R, Yang S, Covey DF, Simpkins JW: Neuroprotective effects of 17betaestradiol and nonfeminizing estrogens against $\mathrm{H} 2 \mathrm{O} 2$ toxicity in human neuroblastoma SK-N-SH cells. Mol Pharmacol 2006;70:395-404.

37 Wang X, Simpkins JW, Dykens JA, Cammarata PR: Oxidative damage to human lens epithelial cells in culture: estrogen protection of mitochondrial potential, ATP, and cell viability. Invest Ophthalmol Vis Sci 2003;44:2067-2075.

38 Jamous MA, Nagahiro S, Kitazato KT, Tamura T, Kuwayama K, Satoh K: Role of estrogen deficiency in the formation and progression of cerebral aneurysms. Part II: experimental study of the effects of hormone replacement therapy in rats. J Neurosurg 2005;103:1052-1057.

-39 Jesmin S, Hattori Y, Sakuma I, Liu MY, Mowa CN, Kitabatake A: Estrogen deprivation and replacement modulate cerebral capillary density with vascular expression of angiogenic molecules in middle-aged female rats. J Cereb Blood Flow Metab 2003;23:181-189.

40 Bain CA, Walters MR, Lees KR, Lumsden MA: The effect of HRT on cerebral haemodynamics and cerebral vasomotor reactivity in post-menopausal women. Hum Reprod 2004;19:2411-2414.

41 Coughlan T, Gibson C, Murphy S: Modulatory effects of progesterone on inducible nitric oxide synthase expression in vivo and in vitro. J Neurochem 2005;93:932-942. 